\title{
Mechanical behaviour of similar and dissimilar AA5182-H111 and AA6016-T4 thin friction stir welds
}

\author{
C. Leitao ${ }^{a}$, R.M. Leal ${ }^{a, b}$, D.M. Rodrigues ${ }^{a, *}$, A. Loureiro ${ }^{a}$, P. Vilaça ${ }^{c}$ \\ ${ }^{a}$ CEMUC, Department of Mechanical Engineering, University of Coimbra, Portugal \\ ${ }^{\mathrm{b}}$ ESAD.CR, Polytechnic Institute of Leiria, Caldas da Rainha, Portugal \\ ${ }^{\mathrm{c}}$ IST, Technical University of Lisbon, Lisbon, Portugal
}

\section{A R T I C L E I N F O}

Article history:

Received 18 December 2007

Accepted 16 April 2008

Available online $\mathrm{xxxx}$

\section{Keywords:}

Taylor welded blanks

Friction stir welding

Aluminium alloys

Thin sheets

\begin{abstract}
A B S T R A C T
The tensile behaviour of similar and dissimilar friction stir welds in $1 \mathrm{~mm}$ thick sheets of two aluminium alloys (AA5182-H111 and AA6016-T4) is analysed in this paper. The heterogeneity in properties across the welds was studied by performing microhardness tests and microstructural analysis. The tensile tests were performed in samples extracted longitudinal and transverse to the weld direction. It was found that the tensile behaviour of the welds depends mainly on the grain size in the TMAZ, for the AA5182-H111 alloy, and on precipitate distribution, for the AA6016-T4 alloy. In all types of welds, the HAZ preserves the same properties of the base materials. The global mechanical behaviour of the AA5182-H111 similar welds is very similar to that of the base material. However, for the AA6016-T4 similar welds and for the AA6016-T4-AA5182-H111 dissimilar welds a 10-20\% strength reduction relative to the base materials and important losses in ductility were reported.
\end{abstract}

() 2008 Elsevier Ltd. All rights reserved.

\section{Introduction}

Increasing industrial concern with ambience and energy is becoming notorious. In this context, friction stir welding (FSW) appeared as an easy, ecologic and promisingly productive weld method that enables to diminish material waste and to avoid radiation and harmful gas emissions, usually associated with the fusion welding processes. The FSW tools are mainly constituted by a small diameter entry probe and a concentric larger diameter shoulder, both usually made of high strength steel.

During the weld process, the FSW tool is rotated and the probe is plunged into the boundary of the adjoining plates. Penetration depth of the probe is controlled by its length and by the tool shoulder, which should be in intimate contact with the plates during welding. The heat generated by friction between the rotating tool and the plates promotes a local increase in temperature and softens the materials under the tool shoulder. At the same time, the plunged rotating probe moves and mixes the softened materials, by intense plastic deformation, joining both in a solid state weld.

According to the temperature attained and the volume of material which is plastically deformed during the welding process, it is usually possible to distinguish two main zones, with different characteristics, in the FS welds: the thermomechanically affected zone (TMAZ), that is constituted by the material plastically deformed during the welding process, and the heat affected zone

\footnotetext{
* Corresponding author. Tel.: +351 239790 700; fax: +351 239790701.

E-mail address: dulce.rodrigues@dem.uc.pt (D.M. Rodrigues).
}

(HAZ), comprising the material affected by the weld thermal cycle but not plastically deformed [1-4]. Frequently, part of the TMAZ presents a recrystallized fine-grained microstructure, resulting from the combination of extremely high plastic deformation and temperature, which is usually called as Nugget. The HAZ of the friction stir welds is of the same nature of the heat affected zone of welds resulting from the fusion welding processes [5].

Despite the large amount of published literature about the FSW process, systematic information does not exist on the influence of the tool and the process parameters on the weld quality for a large range of materials, thicknesses and joint configurations. Until now, FSW industrial application had mostly been restricted to the construction of large components in shipbuilding and aerospace and aeronautics industry [6,7]. The application of this process in the automotive industry is relatively recent and has one of its main fields of interest for the production of aluminium tailored welded blanks (TWB) from very thin sheets [8-13]. In fact, some difficulties continue to restrict the application of TWBs in industry [1417] such as, the difficulty in welding some materials (Al alloys and HSS), the strength reduction in the weld line and the poor formability of the TWBs. The FSW process diminishes some of the weldability problems usually associated with fusion welding processes, due to its low heat input [6]. However, FSW process has limitations in butt-joining thin sheets. The thickness reduction resulting from the forging effect of the shoulder can significantly reduce the mechanical resistance in thin plates (1 mm or less). The presence of micro defects, usually acceptable in thick welds, also pose serious problems in thin plate sheet welds [11]. 
In this work the mechanical behaviour of similar and dissimilar welds obtained by FSW of $1 \mathrm{~mm}$ thick plates of two very popular automotive aluminium alloys, the AA5182-H111 and the AA6016-T4 alloys, are analysed. The AA5182 aluminium alloy, supplied annealed and slightly cold worked (H111), is characterised by its high content on Mg, exhibiting Portevin-Le Châtelier effect under plastic deformation. Due to its excellent formability, especially during deep drawing with a high amount of stretch forming, this material is ideally suited for intricate critical inner panel applications. The second aluminium alloy, the AA6016, was supplied as a solution alloy heat-treated and naturally aged to a stable condition (T4). This aluminium alloy, that presents stable formability in T4 condition, is usually used for car skin sheet applications and for some inner panels.

Due to the different applicability and formability characteristics of these two aluminium alloys, their joining in dissimilar TWBs is very interesting. However, it is well known that the AA5xxx ( $\mathrm{Al}-$ $\mathrm{Mg}-\mathrm{Mn}$ ) and the AA6xxx (Al-Mg-Si) alloys present different characteristics when joined in homogeneous welds by FSW. In fact, for the AA6xxx aluminium alloys, it was already found that the mechanical properties of the FS welds depend mainly on the size, volume fraction and distribution of precipitates in the TMAZ and HAZ. These welds usually experience softening in the TMAZ due to the dissolution and coarsening of the precipitates during welding [3,4,18-24]. Friction stir welding of the AA5xxx aluminium alloys is much less studied than for the precipitation-hardenable alloys, such as the AA2xxx, AA6xxx and AA7xxx alloys. However, it was already found that the mechanical properties of the TMAZ zone of the welds produced from AA5xxx alloys depend mainly on the grain size and on the density of the dislocations after plastic deformation and recrystallisation occurring during welding. When the AA5xxx alloy series are used in the annealed condition the microstructure is stable and usually no softening occurs in the TMAZ and HAZ. In contrast, when these alloys are used in the strain hardened condition, the work hardened structure will readily recover and/or recrystallize during welding, and softening may occur [9,10,25-27].

Due to its remarkably different welding behaviour and its potential industrial interest, the joining of AA5xxx and AA6xxx alloys in dissimilar TWBs, with 2 and $3 \mathrm{~mm}$ plates, was already investigated by several authors [10,25,26,28,29]. Giera et al. [12] performed a statistical investigation on FSW of the AA5182 and AA6016 alloys in similar TWBs. They established window process parameters for joining $1 \mathrm{~mm}$ thick plates of both alloys. Present authors also published a study on the effect of friction stir welding parameters on the microstructure and hardening properties of similar friction stir welds in AA5182-H111 and AA6016-T4 aluminium alloys in $1 \mathrm{~mm}$ thick plates [30]. A comparative analysis of the plastic behaviour of similar and dissimilar welds in these same materials is presented in present paper.

\section{Experimental procedure}

\subsection{Materials and welding}

The chemical nominal composition of the AA5182-H111 and AA6016-T4 base materials used in this investigation is presented in Table 1 . The welds were produced in $1 \mathrm{~mm}$ thick plates of both base materials by using a steel tool with a scrolled shoulder (Fig. 1a) at a $0^{\circ}$ tilt angle. The threaded probe was $3 \mathrm{~mm}$ in diameter and $0.9 \mathrm{~mm}$ long and the scrolled shoulder had $14 \mathrm{~mm}$ in diameter. The welds were performed under position control by moving the tool at $320 \mathrm{~mm} / \mathrm{min}$ travel-
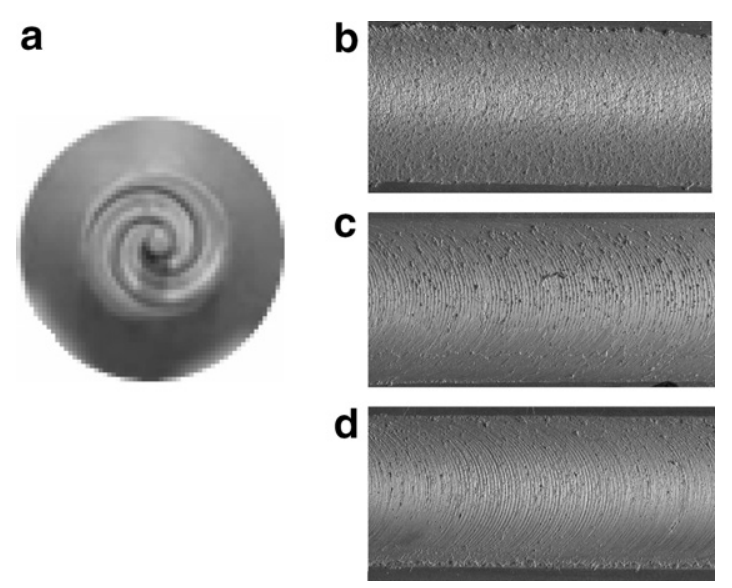

Fig. 1. FSW tool (a) and weld crown appearance for the S55 (b), S66 (c) and D56 (d) welds.

ling speed and $1120 \mathrm{rpm}$ rotational speed. Similar (AA5182-AA5182 and AA6016AA6016) and dissimilar (AA5182-AA6016) TWB's were made by welding the base material plates parallel to the rolling direction of the plates. On the dissimilar blanks, the AA5182 plates were always positioned at the advancing side of the welding tool and the AA6016 on the opposite side. In the next, the samples extracted from the similar welds (AA5182/AA5182 and AA6016/AA6016) will be labelled as S55 and S66, respectively, and the dissimilar weld samples (AA5182/ AA6016) as D56.

Before testing, a qualitative analysis of the welds has been performed and no defects were found in the weld roots. The surface appearance of the weld crowns is shown in Fig. 1b (S55), c (S66) and d (D56). As it can be seen in the figure, no flash was produced during the weld process but the weld surfaces are deeply rough. Small depth striations are observable for the S66 and D56 welds. Thickness reduction in the stirred zone was almost inexistent for all the welds.

\subsection{Hardness testing and microstructural analysis}

The heterogeneity in mechanical properties across the welds was evaluated by performing several microhardness measurements transversely to the weld direction (see Fig. 2). Hardness tests were performed after several weeks of natural aging at room temperature of the welds. Since the hardness measurements can present some scatter even for homogeneous materials, an analysis concerning the sensitivity of the hardness measurements to the hardness testing load was previously performed for both base materials. Based in this study, the test loads used in this work were: $50 \mathrm{~g}$ for the AA5182 base material and S55 similar welds, $100 \mathrm{~g}$ for the AA6016 base material and S66 similar welds and $75 \mathrm{~g}$ for the D56 dissimilar welds. The load holding time was $30 \mathrm{~s}$ in all cases. For each type of sample, the hardness variation across the weld was verified by performing hardness measurements in several positions along the welding directions. In each testing line the hardness measurements were spaced by intervals of $0.25 \mathrm{~mm}$.

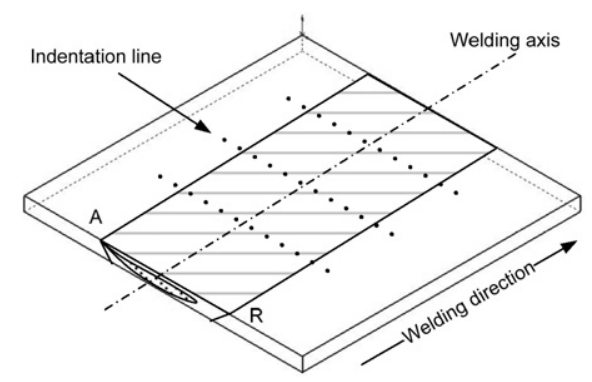

Fig. 2. Specimens were cut from the welds, ground to a suitable surface finishing and microhardness tests performed across the weld.

Table 1

Nominal chemical composition of the base materials (wt\%)

\begin{tabular}{|c|c|c|c|c|c|c|c|c|}
\hline Alloy & $\mathrm{Si}$ & $\mathrm{Fe}$ & $\mathrm{Cu}$ & $\mathrm{Mn}$ & $\mathrm{Mg}$ & $\mathrm{Cr}$ & $\mathrm{Zn}$ & $\mathrm{Ti}$ \\
\hline AA 5182-H111 & $<0.2$ & $<0.35$ & $<0.15$ & $0.2-05$ & $4.0-5.0$ & $<0.1$ & $<0.25$ & $<0.1$ \\
\hline AA6016-T4 & $1.0-1.5$ & $<0.5$ & $<0.2$ & $<0.2$ & $0.25-0.6$ & $<0.1$ & $<0.2$ & $<0.15$ \\
\hline
\end{tabular}


Cross-sectioning of the welds perpendicular to the welding direction for metallographic analysis was also performed. The samples were prepared according to standard metallographic practice and etched with Hatch (macrographs) and Modified Poultons (micrographs) reagent's in order to enable the identification of the different weld zones and its association with the respective hardness values. Metallographic analysis was performed using an optical microscope ZEISS HD 100. In each hardness graph presented in this paper, a macrograph of the weld in study will be shown, together with an indication of the position relative to weld thickness (approximately $0.75 \mathrm{~mm}$ from root face) at which the hardness measurements were performed.

\subsection{Tensile testing}

Tensile specimens of $50 \mathrm{~mm}$ gauge length were machined from the friction stir welded plates parallel (longitudinal) and normal (transverse) to the welding direction, as it is schematized in Fig. 3. The longitudinal tensile samples (labelled S55_L, S66_L, D56_L) were extracted from all the welds in order to test exclusively the stirred material. The transverse tensile specimens (S55_T, S66_T, D56_T) were machined from the TWBs so that the weld was centred in the gauge section and the tensile axis was normal to the welding direction. Longitudinal samples were also extracted from the S55 TWBs, at the advancing and retreating sides of the welds (S55_HAZ_LA and S55_HAZ_LR, respectively), in order to test the HAZ mechanical behaviour.

All the tensile tests were carried out at room temperature at a crosshead speed of $5 \mathrm{~mm} / \mathrm{min}$ using an Instron computer-controlled testing machine. The tensile properties were evaluated by testing three tensile specimens of each type. None of the tensile samples (transverse or longitudinal) were machined in order to eliminate weld surface roughness and its possible influence on the plastic behaviour of the samples.

\section{Results and discussion}

\subsection{Hardness test results}

After a series of 60 hardness measurements, mean hardness values of 67 HV0.1 and 71 HV0.05 have been registered, respectively, for the AA6016 and AA5182 base materials. In Fig. 4, the hardness profiles of the AA5182 base material (grey bar) and S55 similar weld are shown with a matching macrograph of the S55 weld. As it can be seen in the figure, the hardness values measured in the weld are higher than the base material mean hardness (71 HV0.05). The macrograph view of the weld makes clearly visible the TMAZ region, where the highest hardness values were registered, and a sharply defined transition boundary between this region and the HAZ, on the advancing side of the weld. On the retreating side of the weld, a more gradual transition can be seen between these two regions. For thicker welds, it was already reported that the material on the advancing side of the tool, where rotation adds to pin translation, experiences a higher shear rate in a narrower band than on the retreating side, which was indicated as promoting the previously mentioned abrupt change in microstructure and hardness [4].

Relating the hardness profile and the macrograph in Fig. 4 it is possible to conclude that the increase in hardness is restricted to the TMAZ material. A more precise metallographic analysis (Fig. 5) showed that TMAZ is constituted by a region of extremely fine and equiaxed grain structure (the weld nugget), resulting from extensive thermomechanical deformation that induces dynamic recrystallisation and recovery in this region [27], and by a narrow band of highly deformed non-recrystalized grains. In the HAZ, it was observed that the temperatures attained were not sufficient to induce any hardness change of the base material in this region.

The hardness profile and the macrograph relative to a $\$ 66$ similar weld are shown in Fig. 6. According to this figure, the S66 weld softened relative to the base material mean hardness (scattering bar). As for the S55 weld, the hardness variation is clearly located under the toll shoulder area, between the advancing and retreating sides of the weld. The hardness changes abruptly, in the advancing side of the weld, and varies smoothly, from the weld center line to

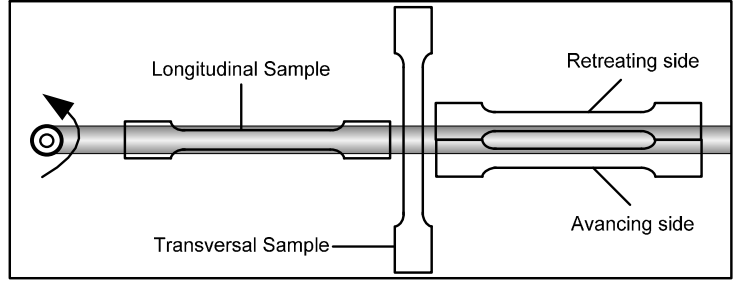

Fig. 3. Tensile test samples (sampling scheme).

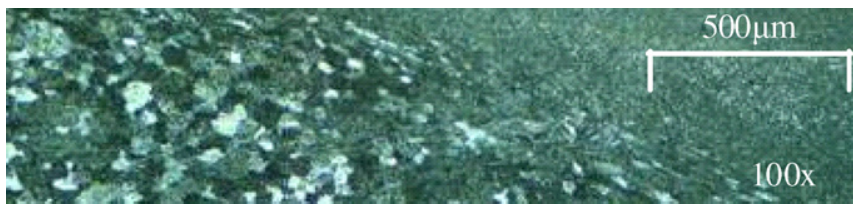

Fig. 5. Optical micrograph showing the microstructure evolution near the advancing side of a S55 weld.

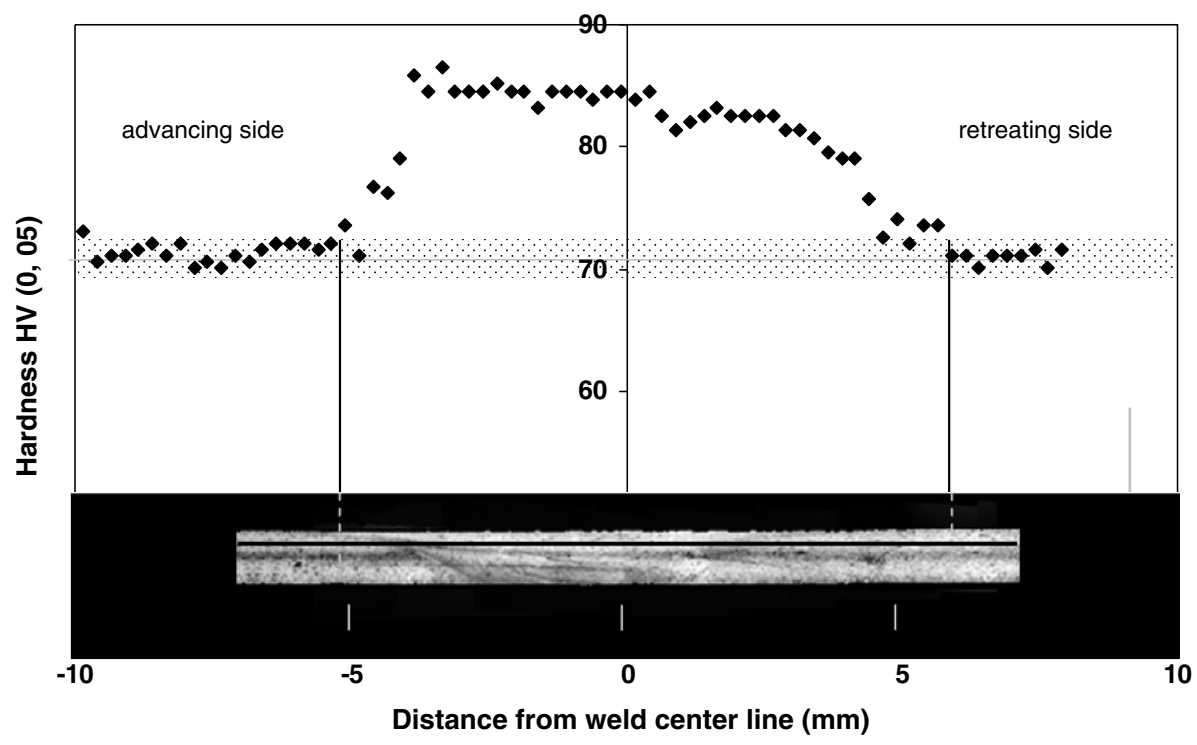

Fig. 4. Hardness profile across a S55 similar weld. 


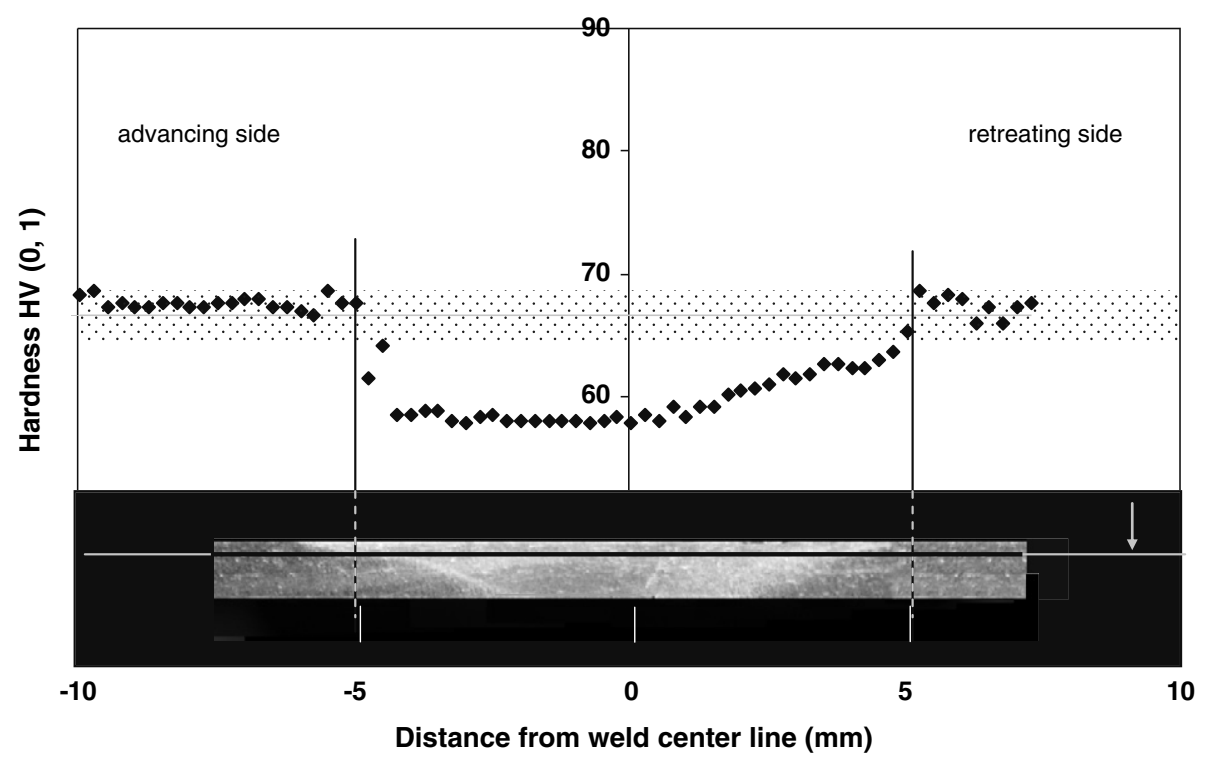

Fig. 6. Hardness profile across a S66 similar weld.

the base material, in the retreating side of the weld. The macrograph of the $S 66$ weld presented in the graph also enables to distinguish the TMAZ region, a sharply defined transition boundary between this region and the HAZ, at the advancing side of the weld, and a smoothest transition at the retreating side. Since the grain in the TMAZ is very refined (Fig. 7a and b), softening in this zone as to be related with the evolution of the strengthening precipitates during welding [13,4,8-24].

The grain structure in the HAZ of the S66 weld (Fig. 7a) is similar to that of the unaffected base material and no hardness decrease was observed in this zone, such as reported by several authors for other alloys of the $6 x x x$ series $[3,19,26,31,32]$. This can be attributable to the low heat input during the weld process. In fact, a more detailed analysis of the TMAZ makes clear the existence of a zigzag oxide array at the center of the weld nugget (Fig. 7b). The formation of the zigzag line, which is constituted by the remnants of the oxide layer on the butt surface of the plates, is usually associated to low heat input parameters [33,34].

Finally, the hardness profile across a dissimilar D56 weld is plotted in Fig. 8 together with mean hardness values (grey bars) for both base materials. As it can be observed in the figure, the hardness variation across the dissimilar weld is much more complex than for the similar ones. In order to facilitate the analysis of the results, mean hardness values for the different weld regions (identified by numbers on the cross-section of the weld) were indicated in the graph. In this figure, some micrographic views of the weld cross-section were also added in order to enable a clear visualization of the weld areas with markedly different microstructural and mechanical characteristics.

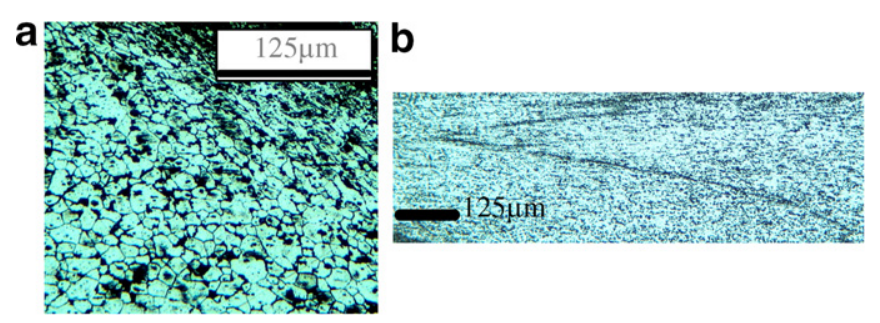

Fig. 7. Optical micrographs showing the microstructure evolution near the advancing side of the S66 weld (a) and the zigzag oxide array at the weld center line.
Analysing the hardness results presented in Fig. 8, it is possible to observe, in the left side of the figure, an abrupt increase in hardness from values characteristic of the AA5182 base material (region 1) to values close to those measured in the TMAZ of the S55 similar weld (region 2). In fact, region 2 of the D56 weld (Fig. 8b) has a very refined and equiaxied grain structure similar to that of the S55 weld nugget (Fig. 5). After region 2, it is possible to observe a strong hardness decrease in the very narrow region 3 that, according to the micrographic analysis (Fig. 8c), has similar grain size to region 2. Chemical analysis of region 3, using EDS and WDS quantitative techniques to measure the Si and Mg contents, show that diffusion of alloying elements between the two materials had occurred in this region resulting in a material with hardness slightly lower than that registered for the AA6016 base material. After region 3, the hardness values in the weld increase again to values close to that measured in region 2 . In fact, the microstructure and chemical composition in region 4 are similar to that of region 2, which is only constituted by AA5182 material transformed during the weld process. Near the weld center line, in region 5, the hardness values abruptly decrease to values close to that characteristic of the AA6016 base material. However, the microstructure in this region of the weld is characterized by much fine and equiaxed grains than the base material (Fig. 8d). In this way, the hardness behaviour has to be a consequence of the redistribution of precipitates during the welding process.

It is important to enhance that despite the same welding parameters were used for welding the similar and dissimilar TWBs, no important hardness decrease occurred in the TMAZ of the D56 dissimilar weld relative to the AA6016 base material, as was registered for the S66 similar weld. Peel et al. [29] studied the evolution of temperature and material mixing during friction stir welding of similar and dissimilar AA5083-AA6082 aluminium alloys. The authors found different plastic flow during similar and dissimilar welding, which naturally explains different mechanical properties for those welds when joined under the same conditions, as observed in present study.

\subsection{Tensile tests results}

The stress-strain curves obtained in the tensile test of samples extracted from the base materials (AA5182-H111 and AAA6016T4), the longitudinal samples from the stirred zone (S55_L, S66_L 

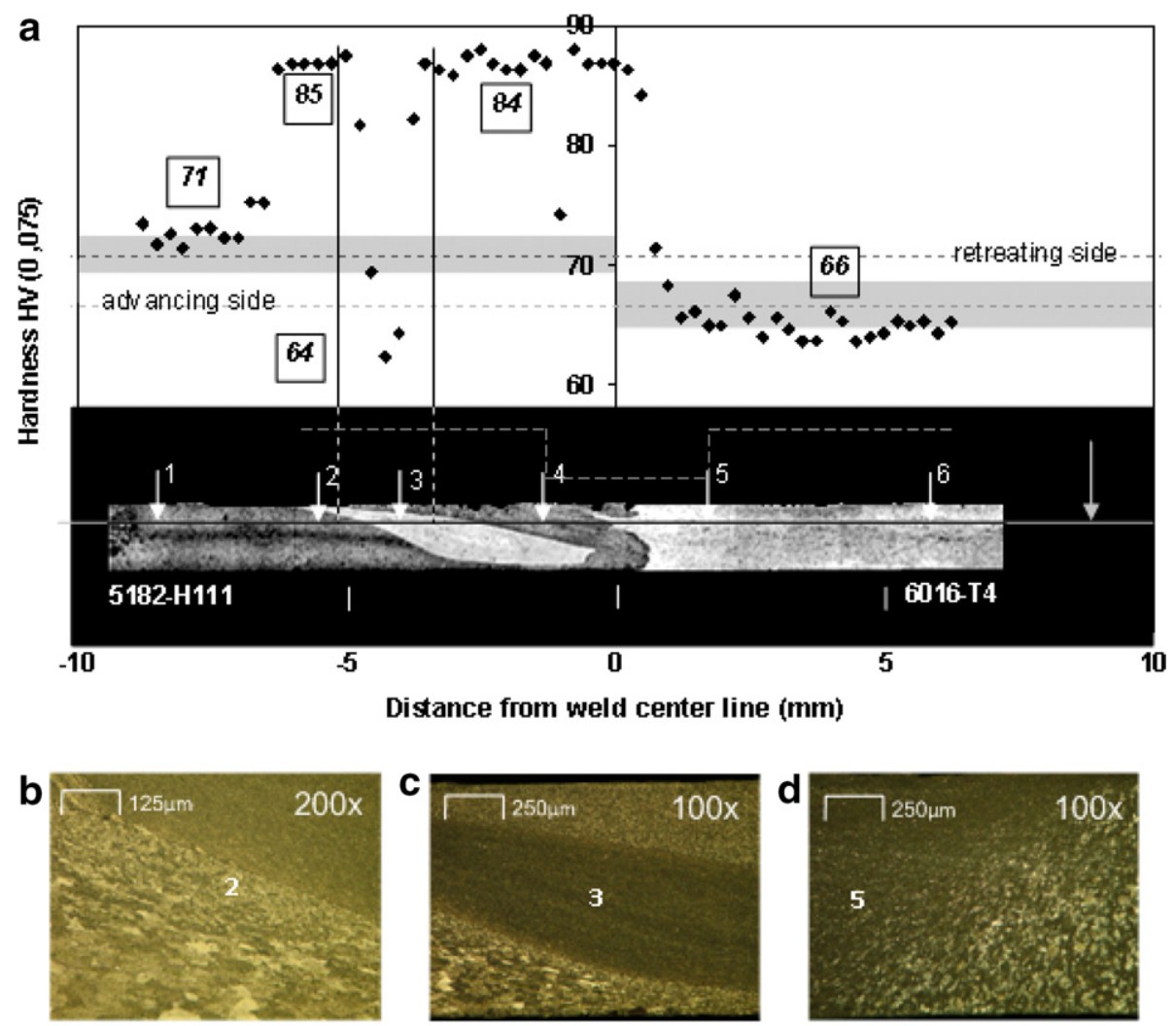

Fig. 8. Hardness profile and cross-section of a D56 dissimilar weld.

and D56_L) and the transverse samples (S55_T, S66_T and D56_T) are plotted in Figs. 9-11 for the S55, S66 and D56 welds, respectively. Since the deformation is highly heterogeneous in the transverse welds, the stress and strain values plotted in the graphs are engineering values calculated from the initial geometry of the samples. It is important to enhance that the reproducibility of the tensile test results presented in this paper was rather good out of three tests performed for each type of samples.

Analysing the graph in Fig. 9, relative to the S55 similar weld, it is possible to see that all the results evidence the Portevin-Le
Châtelier phenomenon characteristic of the 5xxx aluminium alloys. The yield stress registered for the base material sample (AA85182H111) is very similar to that of the transverse samples (S55_T) and lower than that of the longitudinal samples (S55_L). These results are in accordance with the reported hardness results. In fact, for the S55 similar weld, an increase in hardness was registered in the TMAZ which is in accordance with the higher strength values of the S55_L longitudinal sample. On the other hand, in the tensile test of the transverse specimens, since the base material is softer than the stirred material, it was the first to be plastically deformed

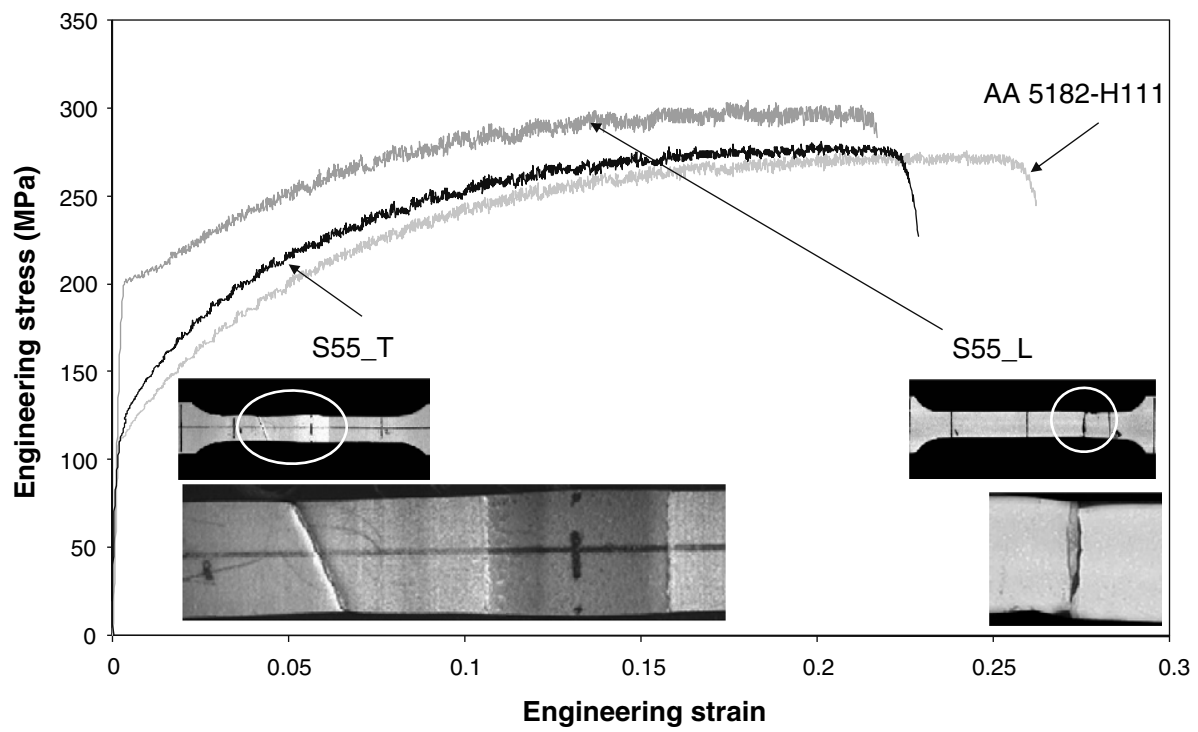

Fig. 9. Engineering stress/strain curves for the AA5182-H111 base material and for the longitudinal and transverse S55 weld samples. 


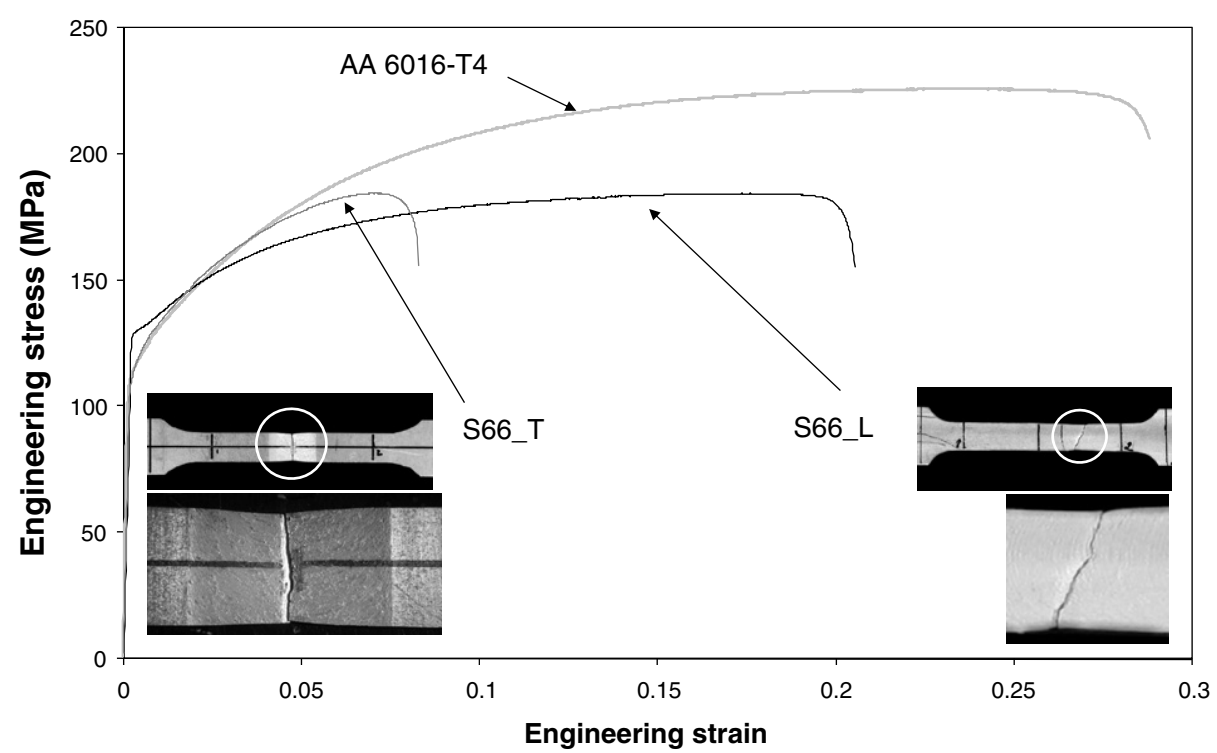

Fig. 10. Engineering stress/strain curves for the AA6016-T4 base material and longitudinal and transverse S66 weld samples.

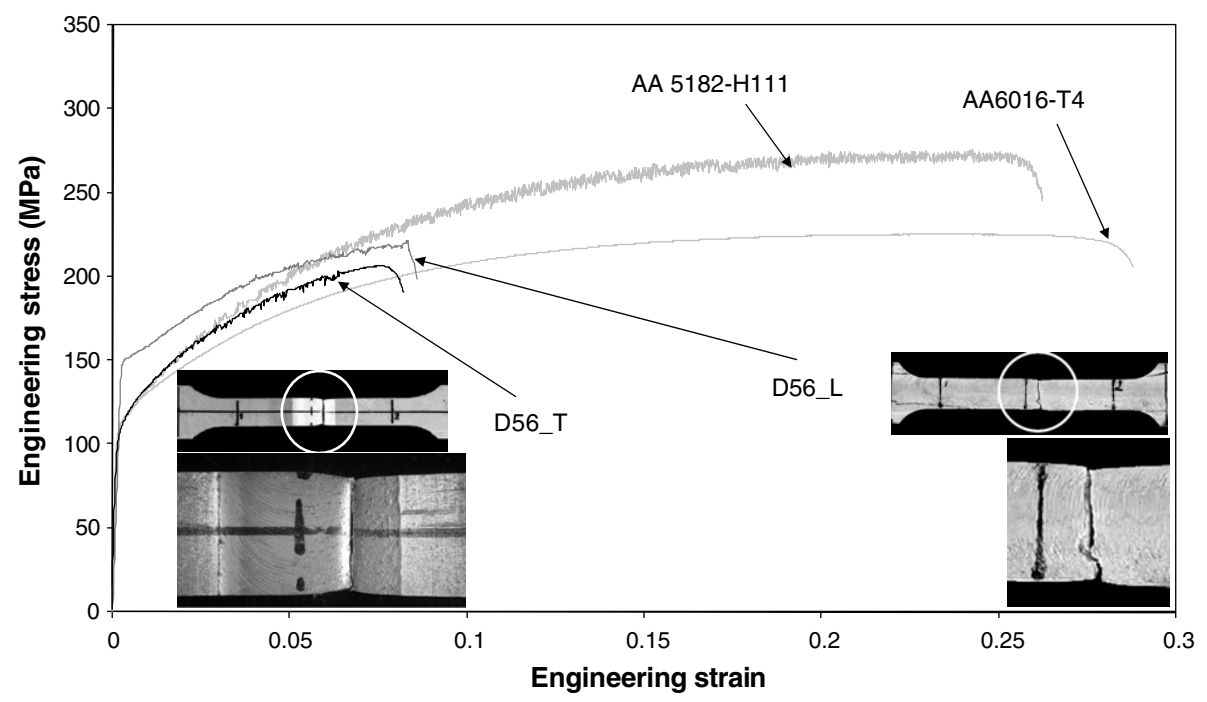

Fig. 11. Engineering stress/strain curves for the AA5182-H111 and 6016-T4 base materials and for the longitudinal and transverse D56 weld samples.

making the yield stress of the transverse sample similar to that of the base material.

It is also important to emphasize that none of the weld samples were subjected to surface flat finishing before testing. In this way, strain localisation at the maximum load (necking), for both weld samples, could be induced by the small surface irregularities and thickness variation characteristics of FS welds. However, it is interesting to denote that both the welded samples (longitudinal and transverse) had almost the same elongation at fracture of the smooth base material samples. This is especially important for the transverse sample that also experiences inhomogeneous behaviour in plastic deformation due to the presence of microstructures with different mechanical properties across the sample. Pictures from the S55_L and S55_T samples after necking in tension are also shown in the figure. These pictures clearly show a $45^{\circ}$ shear fracture, in the base material, far from the weld, for the S55_T weld sample and a straight fracture normal to the load axis for the homogeneous S55_L sample. The shear fracture at $45^{\circ}$ to the principal stress axis is characteristic of homogeneous materials loaded in tension and resulted from the stress concentration in the soft base material. The straight crack at right angles to the stress axis, observed for the longitudinal weld sample, certainly reflects a contribution of the weld grooves in fracture. In fact, surface roughness is a function of the FSW tooling design and the welding parameters and can seriously compromise the plastic and fatigue behaviour of the welds $[3,35]$. In present study, surface grooves did not influence the global ductility of the longitudinal or transverse samples.

The tensile test results relative to the S66 similar weld and to the AA6016-T4 base material are shown in Fig. 10. The results reported in the graph show that the yield stress of the S66_L longitudinal sample is slightly higher than that of the base material, but the hardening capability is lower. This makes that at the maximum load the strength of the stirred material is lower than that of the base material. The S66_L sample has also good ductility, but lower than the base material. This loss in strength in the stirred weld zone, which is in accordance with the hardness results in Fig. 6, is also reflected in the mechanical behaviour of the S66_T trans- 
verse samples that apparently have much lower ductility than the longitudinal weld and base material samples. In fact, plastic deformation concentrates in the weakest zone, the TMAZ, almost preventing the deformation of the parent material in each specimen.

Again, pictures of the tensile samples after fracture in tension are presented in the graph of Fig. 10. Analysing the pictures it is possible to conclude that despite the surface roughness characteristic of the weld, the S66_L samples experienced a $45^{\circ}$ shear fracture characteristic of homogeneous and soft materials. For the S66_T sample a straight failure, coincident with the axis of the soft weld region, can be observed.

The engineering stress-strain curves relative to the dissimilar weld samples (D56_L and D56_T) are presented in Fig. 11. In the same graph are plotted the stress-strain curves relative to both base materials. From the figure it is possible to conclude that the D56_L longitudinal sample has higher yield stress than both base materials but much lower ductility. The high yield stress value can be associated with hardness increase registered in Fig. 8, for the advancing side of the weld. After yielding, the hardening behaviour of the stirred material becomes very similar to that of the softer AA6016 base material and strain localisation occurs after nearly $7 \%$ plastic deformation. As it is possible to observe in the picture of the sample included in the graph, straight fracture surfaces were registered in all longitudinal samples. This behaviour can be related with the highly heterogeneous microstructure of the stirred zone (as it was already shown in Fig. 8), that allied to its very irregular surface finishing, induces non-homogeneous plastic behaviour in the samples.

Analysing the results concerning the transverse weld samples (D56_T), it is possible to observe that its yield stress is very similar to that of the base materials, but its global ductility is much smaller. As it can be observed in the graph, for the transverse samples, necking and fracture occurred in the retreating side of stirred zone, where the AA6016 material is located and lower hardness values were registered (see Fig. 8).

Unlike the similar weld samples (S55 and S66), the dissimilar transverse and longitudinal samples (D56_T and D56_L) had almost the same ductility. Portevin-Le Châtelier effect characteristic of the plastic deformation of the AA5182 base material is also evident in both dissimilar weld curves. However, this effect was less significant for the longitudinal samples since the stirred zone results from the mixing of both base materials and has remarkably different behaviour. Another interesting aspect is that, at the initial stage of plastic deformation, the stress-strain curves for the D56_T samples were superposed to that of the AA5182-H111 base mate- rial indicating that plastic deformation of these samples was not initiated at the soft AA6016 side of the weld.

In order to verify if the HAZ of the friction stir welds has mechanical properties similar to the base material, as shown by the hardness results and microstructural analysis, longitudinal samples were extracted from the HAZ of the S55 similar welds, at the advancing (S55_HAZ_LA) and retreating (S55_HAZ_LR) sides. Tensile test results of the HAZ samples are plotted in Fig. 12 together with those of a S55_L longitudinal sample and of the AA5182-H111 base material. As it can be seen in the figure, the base material and HAZ samples present much lower strength levels than the stirred material (S55_L). The longitudinal sample extracted from the HAZ located at the retreating side of the weld (S55_HAZ_LR) has slightly higher strength than that of the advancing side (S55_HAZ_LA), which in turn has slightly higher strength than the AA5182-H111 base material. Despite these small differences in strength, that can be explained by small amounts of TMAZ material in the HAZ samples (see sampling scheme in Fig. 3), the yield stress and global hardening behaviour of the HAZ samples is very similar to that of the base material and the global ductility is only slightly lower, which confirms that the base material was almost unaffected in the HAZ. The pictures from the fractured surfaces of the HAZ samples after necking show the typical $45^{\circ}$ shear configuration of homogeneous materials.

Finally, the mechanical efficiency of all the welds was characterized by calculating yield $\left(\eta_{\mathrm{ys}}\right)$ and strength $\left(\eta_{\mathrm{Rm}}\right)$ efficiency coefficients defined, respectively, as the ratio between the yield and tensile strength of the welds and the same properties of the parent material. An elongation coefficient $\left(\eta_{\mathrm{e}}\right)$, which is the ratio between the elongation at maximum load of the welded samples and base materials, was also defined. For the D56 dissimilar welds, the base material yield and tensile strength values used in the calculation of the efficiency parameters $\eta_{\mathrm{ys}}$ and $\eta_{\mathrm{Rm}}$ corresponded to those of the weakest base material, the AA6016-T4 alloy. The efficiency results obtained in this study are summarized in Table 2 .

From Table 2 it is possible to conclude that the stirred material of S55 similar weld (S55_L sample) has much higher strength than the base material (88\% higher yield strength and $7 \%$ higher tensile strength) and slightly lower ductility (12\% lower). The mechanical behaviour of the HAZ at the retreating and advancing sides of this weld is also very similar to that of the base material (all efficiency parameters are close to 1 ). These results explain why the overall behaviour of the S55_T samples is also very similar to that of the base material. For the $\mathrm{S} 66$ welds, the stirred material has an important reduction in the tensile strength and ductility relative to the

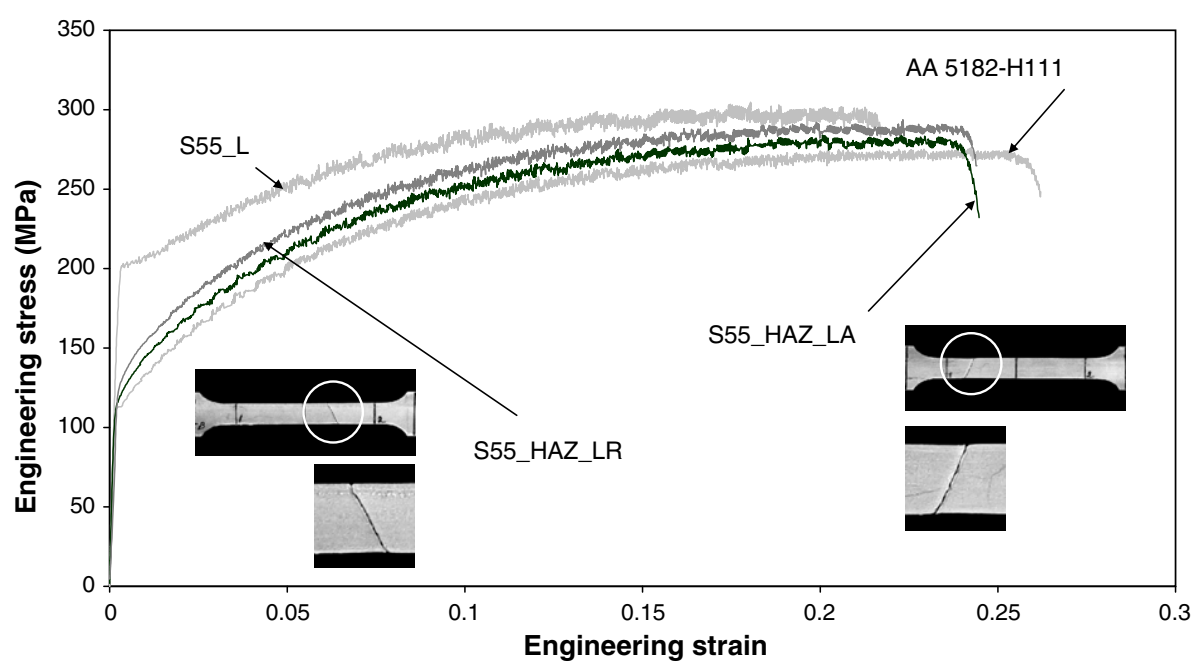

Fig. 12. Engineering stress/strain curves for the S55 similar welds and HAZ. 
Table 2

Tensile test results overview

\begin{tabular}{lllllll}
\hline & $e(\%)$ & $\eta_{\mathrm{e}}$ & $R_{\mathrm{ys}}(\mathrm{MPa})$ & $R_{\mathrm{m}}(\mathrm{MPa})$ & $\eta_{\mathrm{ys}}$ & $\eta_{\mathrm{Rm}}$ \\
\hline 5182-H111 & 24 & - & 108 & 275 & - & - \\
6016-T4 & 24 & - & 104 & 226 & - & - \\
S55_L & 21 & 0.88 & 204 & 296 & 1.88 & 1.07 \\
S55_T & 22 & 0.91 & 118 & 278 & 1.09 & 1.03 \\
S55_HAZ_LA & 24 & 1.00 & 114 & 280 & 1.05 & 1.02 \\
S55_HAZ_LR & 24 & 1.00 & 125 & 287 & 1.04 & 1.07 \\
S66_L & 19 & 0.79 & 134 & 185 & 1.28 & 0.82 \\
S66_T & 7 & 0.29 & 108 & 185 & 1.03 & 0.83 \\
D56_L & 8 & 0.33 & 151 & 222 & 1.45 & 0.98 \\
D56_T & 8 & 0.33 & 116 & 202 & 1.11 & 0.89 \\
\hline
\end{tabular}

$e$ - elongation at fracture; $R_{\mathrm{ys}}-$ yield strength; $R_{\mathrm{m}}-$ tensile strength.

base material which seriously compromises the overall efficiency of these similar welds. In fact, the S66_T samples, display a reduction of $20 \%$ in tensile strength and $70 \%$ in ductility in comparison with the base material. For the dissimilar welds almost no reduction was registered in strength efficiency but important reductions were reported in elongation efficiency (70\%). The elongation at maximum load of the dissimilar weld stirred material (D56_L) is even much lower than that of the similar welds stirred material (S55_L and S66_L). These results indicate that the sudden changes in the mechanical and microstructural properties across the dissimilar weld stirred material can be equivalent to a mechanical notch promoting premature fracture.

\section{Conclusions}

The microstructure and mechanical behaviour of similar and dissimilar friction stir welds in $1 \mathrm{~mm}$ thick sheets of AA5182H111 and AA6016-T4 aluminium alloys were studied in this research. The main results can be summarized as follows:

1. Welds in the alloy AA5182-H111 show an increase in hardness around $20 \%$ in the TMAZ. This hardness change is accompanied by a significant increase in yield stress of the weld material $(88 \%)$ that can be justified by the grain refinement and strain hardening effects. In the HAZ, no substantial changes were observed in the microstructure and mechanical properties relative to the base material, neither in the advancing nor in the retreating sides of the welds. In this case a weld efficiency of $100 \%$ was easily reached.

2. Welds in alloy AA6016-T4 displayed a drop of $15 \%$ in hardness and around $20 \%$ in strength. This strength drop is followed by an important loss in ductility due to the localization of the plastic flow in the weakest TMAZ.

3. The dissimilar welds between both alloys exhibit a hardness variation consistent with the microstructure evolution across the TMAZ. Contrarily to the AA6016-T4 similar welds, no signif- icant decrease in hardness was observed for the dissimilar welds and its strength efficiency is around 90\%. However, its ductility seriously decreases relative to the base materials due to the previously mentioned heterogeneous characteristics of these welds.

\section{Acknowledgements}

The authors are indebted to the Portuguese Foundation for the Science and Technology (FCT) and FEDER for the financial support through the POCI program and to Novelis Switzerland SA for supplying the aluminium sheets.

\section{References}

[1] Mishraa RS, Ma ZY. Mat Sci Eng R 2005;50:1-78.

[2] Murr LE, Flores RD, Flores OV, McClure JC, Liu G, Brown D. Mat Res Innovat 1998;1:211-23.

[3] Scialpi A, De Filippis LAC, Cavaliere P. Mater Design 2007;28:1124-9.

[4] Cabibbo M, Queen HJ, Evangelista E, Spigarelli S, Di Paola M, Falchero A. Mat Sci Eng A. 2007;460-461:86-94.

[5] Ren SR, Ma zy, Chen LQ. Scripta Mater 2007;56:69-72.

[6] Thomas WM, Nicholas ED. Mater Design 1997;18:269-73.

[7] Schofer E. Materialwiss Werktofft 1999;30:693-6.

[8] Sato YS, Sugiura Y, Shoji Y, Park SHC, Kokawa H, Ikeda K. Mat Sci Eng A 2004;369:138-43.

[9] Miles MP, Decker BJ, Nelson TW. Metall Mater Trans A 2004;35:3461-8.

[10] Miles MP, Melton DW, Nelson TW. Metall Mater Trans A 2005;36:3335-42.

[11] Scialpi A, De Giorgi M, De Filippis LAC, Nobile R, Panella FW. Mater Design. 2008;29:928-36.

[12] Giera A, Merklein M, Geiger M. Adv Mater Res 2005;6-8:599-606.

[13] Hirata T, Oguri T, Hagino H, Tanaka T, Wook CS, Tsujikawa M, et al. Key Eng Mater 2007;340-341:1473-8.

[14] Jambor A, Beyer M. Mater Design 1997;18:203-9.

[15] Friedman PA, Kridli GT. J Mater Eng Perform 2000;9:541-51.

[16] Baptista AJ, Rodrigues DM, Menezes LF. Mater Sci Forum 2006;514516:1493-7.

[17] Zadpoor AA, Sinke J, Benedictus R. Key Eng Mater 2007;344:373-82.

[18] Murr LE, Liu G, McClure JC. J Mater Sci 1998;33:1243-51.

[19] Sato YS, Kokawa H, Enomoto M, Jogan S. Metall Mater Trans A 1999;30:2429-37.

[20] Heinz B, Skrotzki B. Metall Mater Trans B 2002;33:489-98.

[21] Lee WB, Yeon YM, Jung SB. Mater Sci Techol 2003;19:1513-8.

[22] Lim S, Kim S, Lee CG, Kim S. Metall Mater Trans A 2004;35:2829-35.

[23] Leal RM, Loureiro A. Mater Sci Forum 2006;514-516:697-701.

[24] Lee WB, Jang HY, Yeon YM, Jung SB. Mater Sci Forum 2004;449-452:601-4.

[25] Shigematsu I, Kwon YJ, Suzuki K, Imai T, Saito N. J Mater Sci Lett 2003;22:353-6.

[26] Peel MJ, Steuwer A, Withers PJ. Metall Mater Trans A 2006;37:2195-206.

[27] Murr LE, Li Y, Flores RD, Trillo EA, McClure JC. Mat Res Innovat 1998;2:150-63.

[28] Steuwer A, Peel MJ, Withers PJ. Mat Sci Eng A 2006;441:187-96.

[29] Peel MJ, Steuwer A, Withers PJ, Dickerson T, Shi Q, Shercliff H. Metall Mater Trans A 2006;37:2195-206.

[30] Loureiro A, Leal RM, Leitão C, Rodrigues DM, Vilaça P. Friction stir welding of automotive aluminium alloys. Weld World 2007;51:433-40 [special issue].

[31] Denquin A, Allehaux D, Campagnac MH, Lapasset G. Mater Sci Forum 2003;426-432:2921-6.

[32] Simar A, Bréchet Y, de Meester B, Denquin A, Pardoen T. Mat Sci Eng A. 2008;486:85-95.

[33] Sato YS, Takauchi H, Park SHC, Kokawa H. Mat Sci Eng A 2005;405:333-8.

[34] Zhou C, Yang X, Luan G. Scripta Mater 2006;54:1515-20.

[35] James MN, Hattingh DG, Bradley GR. Int J Fatigue 2003;25:1389-98. 